\title{
Dormice Glis glis activity and hazelnut consumption
}

\author{
Grazia RODOLFI
}

Rodolfi G. 1994. Dormice Glis glis activity and hazelnut consumption. Acta theriol. 39: $215-220$.

The circadian and monthly activity rhythms of dormice Glis glis (Linnaeus, 1766) and their foraging for a preferred food source (hazels) have been studied. Dormice showed a monophasic pattern of activity from June to early November. The daily active period started from or after sunset, and ended usually before sunrise. In June and September, however, the foraging was prolonged ca $1 \mathrm{hr}$ after sunrise. This suggests that the active phase is limited by the endogenous cycle of dormouse rather than by photoperiod. Hazelnut intake began in June before the fruits were ripened, and went on until the supply was exhausted, in August.

Dipartimento di Biologia Evoluzionistica e Sperimentale, sede di Zoologia, Via San Giacomo 9, 40126 Bologna, Italy

Key words: Glis glis, activity rhythm, hazelnut foraging

\section{Introduction}

Dormice Glis glis (Linnaeus, 1766) are gregarious, nocturnal rodents, found in both deciduous woods and areas inhabited by man, sometimes causing extensive damage to fruit trees (Platt and Rowe 1964, Santini 1983). They can be very numerous in country settlements too, entering above the wooden-beam ceilings and damaging the buildings.

Despite their economic importance, few studies on dormouse ecology and behaviour in Italy have been published. This paper presents a field study on the activity rhythm of a dormouse population of about 60 individuals. I also considered their seasonal consumption of hazelnuts, as the favourite food of this species (Holišova 1968, Grodziński and Sawicka-Kapusta 1970, Gębczyński et al. 1972): hazelnuts have a high caloric content $(7984 \mathrm{cal} / \mathrm{g}$ in dry weight seeds minus coat; cf Grodziński and Sawicka-Kapusta 1970), a high edible/inedible share ratio (Parisi $1977)$ and great metabolizable energy $(88.1 \pm 0.7 \%$ of the gross hazelnut energy; cf Gębczyński et al. 1972). Moreover, dormice quickly handle and open hazelnuts, yielding great energy production per unit of time. All these factors make hazels an attractive food source.

\section{Methods}

The study was carried out between September 1987 and August 1989, in the Centro Interdipartimentale Sorelle Clarke, situated in Bagni di Lucca, Tuscany (196.2-213.8 m a.s.1.), a 26 ha 
area of hilly, mixed woodland and a human-inhabited area, formed by a garden and some cultivated plots. There were several food items for rodents both in the woodland (pine cone seeds, chestnuts) and in the anthropogenic area (apples, cherries, pears, hazelnuts, walnuts, magnolia fruits and cypress cone seeds). However, from September 1987 I concentrated the field work in the man-cultivated sites, as during June-August 1987 a series of preliminary observations showed that there was very little dormouse activity in the woodland.

The activity rhythm of the population was studied in September 1987, May-October 1988, May, June and August 1989, for ten days every month. The observations were carried out continously, recording the sounds of activity (sounds caused by dormice moving into the tree leafy branches when foraging, travelling or during reproductive activity, as well as the sounds of their calls), time, number of trees, location and behaviour - when possible - of any animal seen. The method used was "continuous recording" (Martin and Bateson 1988). To confirm the activity report, dormice were floodlighted only at the end of the preagreed observation period, so as not to interfere with their behaviour.

The daily activity rhythm was expressed each month, all the data collected during the period under consideration, using both sightings and activity signals (sounds). Activity was calculated as the number of dormice seen per hour of observation time. Effects of population size were removed from the level of activity, dividing activity per hour by the number of dormice present in the population and multipled by 100 (Activity index; Thompson 1976). Data were analysed monthly for each hour, as the mean of all activity indices.

To define the amount of hazelnuts consumed by dormice, several daily samplings of hazelnut remains were carried out from June to August 1988 and 1989, with the use of a green waterproof cloth suspended just under the canopy of the hazel trees. I collected the hazelnut remains that fell on this cloth when all the dormice returned to their nests. Sampling occurred for 3 days every one or two weeks. Hence the data were analysed per 15 day sampling, the amount of hazelnuts consumed being expressed as a percentage of all food remains.

\section{Results and discussion}

Dormice showed an annual cycle of activity lasting about five months, from early June to early November. This period of activity is similar to the findings for dormice in different parts of their distribution area: Gaisler et al. (1977) reported that dormice first occurred in nest boxes on 31 May, the last occurrence being on 14 October (Czechoslovakia, 400-950 m a.s.l.). Pilastro (1990,1992) stated that dormice used nest boxes from mid-May to early November, and that all adults started hibernating before the last week of October, three weeks before the most recent young of the year (Colli Berici, Vicenza, Italy, 200-300 m a.s.l.).

The results refer to September 1987, May-October 1988, May, June and August 1989. In May 1988 no activity was observed either at the beginning or the end of the month. Activity started in June, maintaining the same level of activity per hour (average of activity index). July showed slightly higher values in the first part of the night, with a decrease in the last three active hours (Fig. 1). From the first days of the month, dormice began to reduce the activity duration until August, when the minimum number of active hours per day (four hours) was reached, as was the greatest mean activity index. As there were no apparent exogenous factors exerting an activity reduction, so the rapid decrease may have been a consequence 
of births and nursing the young a this time (Gaisler et al. 1977, Pilastro 1992). In September, activity increased considerably, reaching the highest number of active hours ( 11 hours) and the minimum number of sightings ( 22.2 per day). In spite of the length of the active period, a rather high and continuous activity per hour was maintained, probably caused by intensive feeding prior to hibernation (Mrosovski 1966, Franco 1990). By early October the activity values and the number of active hours began to decrease rapidly. Moreover, October showed an activity pattern with a gap of two hour in the middle of the night, between a 5 -hour and a 2-hour active period. This was recorded both by the absence of vocalizations and by direct sightings, but also by observations on some dormice coming back to the nests and coming out after about 2 hours. By the second half of November no more activity signs were recorded. Overall, the activity pattern

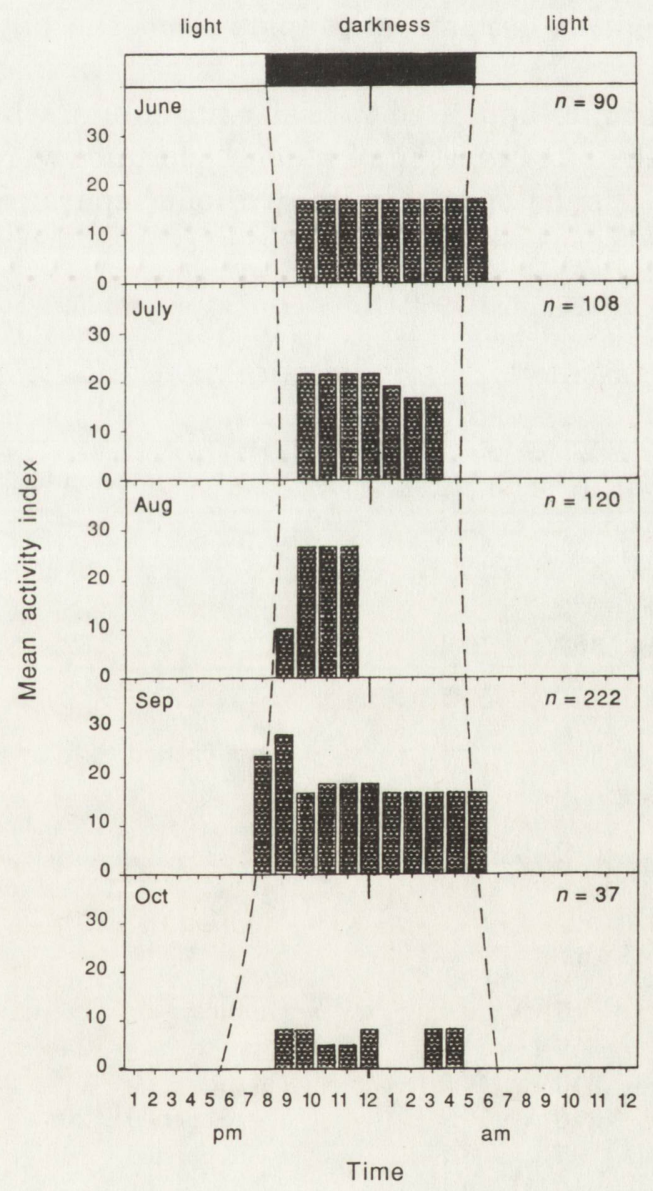

Fig. 1. Activity rhythm over a year (1988), expressed as mean activity index. The times of sunset and sunrise (Civil Twilight) are indicated by dotted lines. The number of dormice sighted $(n)$ per 10 days of field work is given in the top right-hand of the figures. 
of 1988 was monophasic, the only exception being October, possibly due to a rest break.

Data from May 1989 showed a very slight indication (2 hours) of animal arousal. June 1989, in comparison with 1988, showed a decrease both in the length of the active period (9 hours in 1988; 6 hours in 1989) and of the mean activity indices per hour (16.7 in 1988; 8.3-11.1 in 1989). Also in August 1989 the level of activity per hour was reduced (10-26.7 in 1988; 13.3-18.8 in 1989) as well as in September 1987 (20-21.7 in $1987 ; 16.7-28.3$ in 1988).

There was no correlation between the lenght of night-time and the 1988 monthly percentage of active period (Sperman rank correlation: $n=6, r_{\mathrm{s}} \mathrm{ns}$ ), as well as the onset and the end of activity were not linked to sunset and daybreak respectively. Dormice were active before sunset in September 1987. They were active after sunrise in June and September 1988. These observations suggest that the endogenous cycle may become uncoupled from the daybreak and nightfall "zeitgeber".

In the summer, dormice appeared to prefer hazelnuts, which began to ripen at this time of the year. Unlike other small rodents, dormice were able to tear, handle and eat away whole groups of hazelnuts, without separating fruits one by one,

Table 1. Hazelnut intake in 1988 and 1989. Number of samples refers both to groups of hazelnuts (groups of 4, 3, 2 nuts) and single nuts.

\begin{tabular}{llll}
\hline \multirow{2}{*}{ Date } & \multicolumn{3}{c}{ Nuts intake } \\
\cline { 2 - 4 } & $\begin{array}{l}\text { Sample } \\
\text { size }(n)\end{array}$ & $n$ & $\%$ \\
\hline
\end{tabular}

\begin{tabular}{lll}
\hline \multicolumn{4}{c}{ Groups of } \\
\cline { 2 - 3 } & \multicolumn{4}{c}{ nuts $\quad 3$ nuts $\quad 2$ nuts 1 nut } \\
\hline
\end{tabular}

1988; year crop = 1712 nuts

$\begin{array}{crrc}\text { June } 1-15 & 0 & 0 & 0 \\ 16-30 & 110 & 154 & 10.6 \\ \text { July 1-15 } & 352 & 422 & 29.2 \\ 16-31 & 630 & 731 & 50.6 \\ \text { August 1-15 } & 83 & 139 & 9.6 \\ 16-31 & 0 & 0 & 0 \\ \text { Total } & 1175 & 1446 & 100 \\ \text { Percent of year crop } & & & 84.5\end{array}$

$\begin{array}{lrrrr}n \text { samples } & 8 & 43 & 237 & \\ \begin{array}{l}n \text { nuts } \\ \text { of these: }\end{array} & 32 & 129 & 474 & 887 \\ \quad \text { opened } & 25 & 114 & 420 & 887 \\ \text { not opened } & 7 & 15 & 54 & 0\end{array}$

1989; year crop = 1192 nuts

$\begin{array}{crrc}\text { June } 1-15 & 0 & 0 & 0 \\ 16-30 & 223 & 266 & 24.5 \\ \text { July 1-15 } & 445 & 510 & 46.9 \\ 16-31 & 190 & 216 & 19.9 \\ \text { August 1-15 } & 61 & 95 & 8.7 \\ 16-31 & 0 & 0 & 0 \\ \text { Total } & 919 & 1087 & 100 \\ \text { Percent of year crop } & & & 91.2\end{array}$

$\begin{array}{crrr}n \text { samples } & 6 & 40 & 131 \\ \begin{array}{c}n \text { nuts } \\ \text { of these: }\end{array} & 24 & 120 & 262 \\ \quad \text { opened } & 20 & 98 & 228 \\ \text { not opened } & 4 & 22 & 34\end{array}$

742

0


gnawing and then tearing away the nut pericarp (G. Rodolfi, pers. obs.). Of the five hazels present on the woodland border line, only the one producing the greatest number of fruits, was used by the dormouse population. This tree produced a greater crop in 1988 (1712 nuts) than in 1989 (1192 nuts), consequently the total number of meal samples (single or grouped hazelnuts), was greater this same year for the dormouse population (Table 1), while there was no difference between the years as to the ratio of hazelnuts opened by dormice between single and groups of fruits (Wilcoxon matched pairs signed-ranks test: $n=8, \mathrm{~T}=6.5$, ns, two-tailed).

Hazelnut consumption by the dormouse population occurred from early June to late August, in both years of field work. During the first half of June they seldom appeared at any of the cultivated plots, being active especially in the garden, where they exploited cypress Cupressus sempervirens cones, but by the second half of June, when the fruits were still unripe but easily opened because the pericarps were still tender, they began to feed on hazelnuts. Food intake over the last fifteen days of June in 1989 was almost twice as much as in 1988 (Table 1). Moreover, the peak intake in 1989 was fifteen days earlier (15 July) than in 1988 (31 July). Feeding went on every night until the food supply ran out, which occurred by the end of August, both in 1988 and in 1989, while other hazels had a still intact crop. Total dormouse intake of nuts corresponded to $84.5 \%$ and $91.2 \%$ of the two-year crops of the preferred hazel tree.

Dormouse intake was always conspicuous, reaching a mean of 31.7 and 20.5 hazelnuts per day in the second part of July 1988 and in the first part of July 1989, respectively. A pressing hazelnut intake occurred when fruits were still unripe or not yet fully ripe, exhausting the resource in a short time. From late August, when hazelnuts were no longer available, the dormouse population was again fairly uniformly dispersed in cypresses, a garden horse-chestnut tree, magnolias and fruit trees on the cultivated sites, but it was the cypress cones amply distribyted over the whole anthropogenic sites - that became the most important food supply. Other fruits were utilized by dormice only to a lasser extent.

\section{References}

Franco D. 1990. Feeding habits of a dormouse population (Myoxus glis) of the Asiago Plateau (Venetian prealps). Hystrix 2: 11-22.

Gaisler J., Holas V. and Homolka M. 1977. Ecology and reproduction of Gliridae (Mammalia) in Northern Moravia. Folia Zool. 26: 213-228.

Gębczyński M., Górecki A. and Dróżdż A. 1972. Metabolism, food, assimilation and bioenergetics of three species of dormice (Gliridae). Acta theriol. 21: 271-294.

Grodziński W. and Sawicka-Kapusta K. 1970. Energy values of tree-seeds eaten by small mammals. Oikos 21: 52-58.

Holišova V. 1968. Notes on the food of dormice (Gliridae). Zool. Listy 17: 109-114.

Martin P. and Bateson P. 1988. Measuring behaviour. Cambridge University Press, Cambridge: $1-200$.

Mrosovski N. 1966. Acceleration of annual hibernating cycle to 6 weeks in captive dormice. Can. J. Zool. 44: 903-910. 
Parisi V. 1977. Ambiente e alimentazione. Etas libri, Milano: 1-137.

Pilastro A. 1990. Studio di una populazione di ghiro (Glis glis, Linnaeus) in un ambiente forestale dei Colli Berici. Lavori Soc. Ven. Sc. Nat. 15: 145-155.

Pilastro A. 1992. Communal nesting between breeding females in a free-living population of fat dormouse (Glis glis, L.). Boll. Zool. 59: 63-68.

Platt F. B. W. and Rowe J. J. 1964. Damage by the edible dormouse (Glis glis) at Wendorer Forest (Chilterns). Quarter. J. Forestry 58: 228-237.

Santini L. 1983. I roditori italiani di interesse agrario e forestale. C.N.R. Progr. Fin. Prom. Qual. Amb. AQ/1/232 Padova: 89-94.

Thompson D. C. 1976. Diurnal and seasonal activity of the grey squirrel (Sciurus carolinensis). Can. J. Zool. 55: 1185-1189.

Received 16 June 1993, accepted 26 April 1994. 